\title{
Erratum to: Non-surgical Management of a Mycotic Internal Iliac Artery Aneurysm in a Neonate: Case Report and Review of the Literature
}

Philippa Jackson $^{1}$ (D) Helen Bryant ${ }^{2} \cdot$ Jeanette Kraft $^{3} \cdot$ Sean O'Riordan ${ }^{4}$. Jai Patel $^{3}$ - Grainne Bourke ${ }^{1}$

Published online: 19 May 2017

(C) Springer Science+Business Media New York and the Cardiovascular and Interventional Radiological Society of Europe (CIRSE) 2017

\section{Erratum to: Cardiovasc Intervent Radiol} DOI 10.1007/s00270-017-1595-3

The last author (Grainne Bourke) was mistakenly listed with an additional affiliation (Karolinska Institutet) in the published article and should be listed with only one affiliation as shown in this erratum.

The online version of the original article can be found under doi:10.1007/s00270-017-1595-3.

Philippa Jackson

Philippa.jackson6@nhs.net

1 Department of Plastic Surgery, Leeds General Infirmary, Great George Street, Leeds LS1 3EX, UK

2 Department of Trauma and Orthopaedics, Leeds General Infirmary, Great George Street, Leeds LS1 3EX, UK

3 Department of Radiology, Leeds General Infirmary, Great George Street, Leeds LS1 3EX, UK

4 Department of Paediatrics, Leeds General Infirmary, Great George Street, Leeds LS1 3EX, UK 